\title{
Entre (des)encontros: Tensionando práticas no cuidado em saúde de crianças e jovens
}

Entre (des)encuentros: Tensionando practicas em el cuidado em salud de niños y jovenes Among (mis)encouters: Tensioning practices in health care of children and youngsters

\author{
Camila Caroline da Silva Inácio \\ ORCID: https://orcid.org/0000-0002-8434-4366 \\ Centro Universitário Metodista do Sul, Rio Grande do Sul/Brasil \\ Lutiane de Lara \\ ORCID: https://orcid.org/0000-0002-9075-9824 \\ Centro Universitário Metodista do Sul, Rio Grande do Sul /Brasil
}

\begin{abstract}
Declaração de Direito Autoral
A submissão de originais para este periódico implica na transferência, pelos autores, dos direitos de publicação impressa e digital. Os direitos autorais para os artigos publicados são do autor, com direitos do periódico sobre a primeira publicação. Os autores somente poderão utilizar os mesmos resultados em outras publicações indicando claramente este periódico como o meio da publicação original. Em virtude de sermos um periódico de acesso aberto, permite-se o uso gratuito dos artigos em aplicações educacionais e científicas desde que citada a fonte conforme a licença CC-BY da Creative Commons.
\end{abstract}

\section{Resumo}

Este trabalho busca mapear como se constituem afetos e suas intensidades através da experiência no processo de constituição do cuidado em saúde de crianças e jovens em uma Equipe Especializada em Saúde da Criança e do Adolescente (EESCA) situada em um Centro de Saúde na cidade de Porto Alegre (Rio Grande do Sul), além de procurar brechas que permitam o surgimento de outros sentidos para a atuação no campo da saúde. Faz-se a escolha da cartografia como método potente capaz de mapear a produção de modos de subjetivação da cartógrafa, de crianças, jovens e suas famílias, em seus movimentos de territorialização e desterritorialização cotidianos. No decorrer do trabalho buscase realizar o deslocamento de postura enquanto pessoa atuante na área da saúde, de forma a jogar-se mais intensamente nos cenários em que ocorrem as práticas para que nos encontros torne-se possível produzir afetos que afirmam a potência de vida dos sujeitos e não os enquadrem em um ideal de saúde dominante.

Palavras-chaves: Cuidado em saúde de crianças e jovens, Cartografia, Afetos.

\section{Resumen}

Este trabajo intenta mapear y tensionar las practicas de cuidado en salud de niños y jovenes en un Equipo Especializado en Salud del Niño y Adolescente (EESCA en el acrónimo original en portugués) situado en un Centro de Salud en la ciudad de Porto Alegre (Rio Grande do Sul), además de buscar brechas que permitan el surgimiento de otros sentidos para la actuación en el campo de la salud. La cartografía es escojida como un método potente y capaz de mapear la producción de modos de subjetivación y desterritorialización diarios. En el transcurso del trabajo intentase realizar el deslocamiento de postura como persona actuante en el área de la salud, de forma que se juegue más intensamente en los escenarios en lo que se producen las prácticas para que en los encuentros tornese posible produzir afectos que afirman la poténcia de vida de los sujetos e no los enquadren en un ideal de salud dominante. 
Palabras claves: Cuidado en salud de niños y jóvenes, Cartografia, Afetos.

\begin{abstract}
This work intends to map and stress the practices of health care of children and young people in a Specialized Team on Child and Adolescent Health (EESCA in the original portuguese acronym) located in a Health Center in the city of Porto Alegre (Rio Grande do Sul), in addition to looking for loopholes that allow the emergence of other meanings for the health field. Cartography is chosen as a powerful method capable of mapping the production of modes of subjectification of the cartographer, children, young people and their families, in their movements of territorialization and deterritorialization everyday. In the course of the work, the goal is to perform the displacement of posture as an active person in the health area, in order to play more intensely in the scenarios in which the practices occur so that in the encounters it becomes possible to produce affections that affirm the power of life and do not fit into a dominant health ideal.
\end{abstract}

Keywords: Health care for children and young people, Cartography, Affections.

\section{Introdução}

Este texto percorre as entranhas de cenas e processos experienciados por quem o escreve. Os quais fazem parte tanto de um passado, quanto do presente e já do futuro, na medida em que embaralham o tempo e os sentidos que buscam enlouquecidamente serem outros, serem construção nunca finalizada. Experiências de estágios curricular e extracurricular do Curso de Psicologia, no período de junho de 2016 a junho de 2018, que ocorrem pelos corredores de uma Equipe Especializada em Saúde da Criança e do Adolescente (EESCA), localizada no Centro de Saúde Vila dos Comerciários, na cidade de Porto Alegre. As EESCAs surgem em 2011 com a unificação entre os Núcleos de Atenção à Saúde da Criança e Adolescentes em Idade Escolar (NASCA) e as equipes de saúde mental responsáveis por atender este público (Porto Alegre, 2015). Desta forma, o propósito da unificação foi atender de maneira integrada, através das especialidades em saúde que compõem as equipes atuantes. Seu objetivo enquanto serviço de atenção secundária é promover, como pertencente a Rede de Atenção à Saúde (RAS) do Sistema Único de Saúde (SUS), o acolhimento e atendimento especializado e integral à crianças e jovens, de 0 à 17 anos, que residam na região de abrangência de cada equipe.
Por entender que tais equipes são importantes para que se possa oferecer um atendimento integral e singular ao sujeito que acessa o serviço, o presente trabalho foi se constituindo através do questionamento e da ampliação das possibilidades do que uma EESCA pode desenvolver enquanto parte integrante dos serviços de saúde mental. Tal composição do trabalho foi sendo possível mediante o método cartográfico como exercício metodológico, na tentativa de instigar o olhar da pessoa que o compõe e percorre os caminhos do local que fez disparar a escrita.

No início da experiência de estágio que gera este trabalho, o desassossego ao lançar o olhar sobre as práticas da área da saúde voltadas para crianças, jovens ${ }^{1}$ e suas famílias foi constante. Práticas estas que se traduzem desde um acolhimento ao entrar para ser atendido em um serviço de saúde, bem como em nossas relações com colegas no ambiente de cuidado, a maneira como recebemos encaminhamentos, como nos reportamos para os outros serviços de saúde, além de nossa própria implicação com o que acreditamos

1 Faz-se o uso do termo “jovem" pelo entendimento de que a palavra "adolescente" carrega consigo "um determinado jeito correto de ser e de estar no mundo, uma natureza intrínseca a essa fase do desenvolvimento humano" (Coimbra, Bocco \& Nascimento, 2005, p. 6). 
estarmos realizando naquele local. A partir disto, com o passar dos dias, foi tornando-se cada vez mais indispensável para que a experiência não se deixasse ser tomada por afetos paralisantes e normatizantes. Afetos no sentido proposto por Espinoza (2009), no que o autor esclarece que "por afeto compreendo as afecções do corpo, pelas quais sua potência de agir é aumentada ou diminuída, estimulada ou refreada [...]." (Espinoza, 2009, p. 98). O filósofo ainda denota que "a tristeza diminui ou refreia a potência de agir do homem [...] uma vez que a alegria aumenta e estimula a potência de agir." (Espinoza, 2009, p. 123). Desta maneira, o autor entende o corpo como potência e as afecções como o encontro entre os corpos, onde no encontro com o(s) outro(s), somos afetados.

$\mathrm{Na}$ linha do que propõe Espinoza (2009), a composição dos afetos que proporcionam o aumento de nossa energia dialoga com a noção de experiência. Vale esclarecer que experiência não é tudo o que nos acontece cotidianamente, mas o que disto tudo, nos toca e faz-nos experienciar (de fato) a vida e seus enlaces e faz aumentar nossa potência de agir. Conforme Larrosa (2002) "a velocidade com que nos são dados os acontecimentos e a obsessão pela novidade, pelo novo, [...] impedem a conexão significativa entre acontecimentos" (Larrosa, 2002, p. 23). Desta forma, ao falar sobre a experiência, o autor elucida que está "é o que nos passa, o que nos acontece, o que nos toca. Não o que se passa, não o que acontece, ou o que toca. A cada dia se passam muitas coisas, porém, ao mesmo tempo, quase nada nos acontece." (Larrosa, 2002, p. 21). Dentro desta passagem, fica ainda mais em evidência o quão importante é tomarmos o que nos ocorre como experiências, como algo que nos atinge de maneira profunda.

Era urgente problematizar como formavam-se as práticas e também a construção de demandas do serviço, bem como procurar caminhos que fossem possíveis percorrer sem que se fechasse o olhar para procedimentos padronizados. Com isto, ainda no primeiro semestre em que a cartógrafa frequentava o local de estágio, percebeu-se capturada pelo que buscava tensionar. Tal captura emergiu a partir da escrita de um ensaio sobre a experiência de estágio, como trabalho apresentado à supervisão acadêmica. Os relatos que apareciam no decorrer do ensaio, produzido entre os meses de agosto e novembro do ano de 2016, percorriam um caminho de estranhezas ao apontar que tudo aquilo que acontecia no campo de estágio parecia não fazer sentido. Até este ponto, não era possível o exercício de invenções para escapar do que tanto problematizava.

A tentativa de pensar as práticas em saúde e seus funcionamentos constitui-se tarefa difícil, pois o processo de dar-se conta é dolorido e exige mais do que simplesmente relatar algo do qual não se concorda. Ao passo em que a cartógrafa foi provocada a pensar e questionar seu próprio pensamento sobre o que ali ocorria conseguiu, gradativamente, desvencilhar-se da nulidade que $o$ ato de apenas isolar-se dos ambientes que a incomodavam a amarrava. Guareschi, Lara, Azambuja \& Gonzales (2011) esclarecem que o processo de pensar o pensamento "estabelece uma exterioridade ao próprio pensamento $[\ldots]$ torna possível que o pesquisador tome como objeto de estudo o próprio ato de pensar e a possibilidade da própria representação." (Guareschi., Lara, Azambuja, \& Gonzales, 2011, p. 198). Neste ponto foi possível para a cartógrafa sentir e transformar seus pensamentos e ações para que não ficasse presa no niilismo ${ }^{2}$ que tentava lhe monopolizar. Iniciou-se então o entendimento de que para serem outras as práticas que tanto pareciam ser normatizantes e individualizantes, a implicação de quem lança este olhar de estranheza faz-se necessário. Segundo Lourau (2004),

$$
\begin{array}{llcl}
\text { A implicação deseja pôr fim às } & \text { àn } \\
\text { ilusões } & \text { e } & \text { imposturas } & \text { da }
\end{array}
$$

\footnotetext{
${ }^{2} \mathrm{O}$ niilismo enquanto expressão de que nada mais faz sentido para o ser humano, restando apenas uma vontade de nada, ainda que siga existindo vontade (Nietzsche, 1998).
} 
"neutralidade" analítica, herdadas da psicanálise e, de modo mais geral, de um <<cientificismo>> ultrapassado, esquecido de que, para o "novo espírito científico", o observador já está implicado no campo da observação, de que sua intervenção modifica o objeto de estudo, transforma-o. (Lourau, 2004, pp. 8283).

Desta maneira, isolar-se daquilo que causa estranheza, do que assusta e tenta paralisar mudanças, não faz ser possível abrir condições para novos caminhos, ao ponto em que precisamos exercitar a desterritorialização ${ }^{3}$ do que nos é imposto, mover o concreto que parece tão rígido ao olhar, mas que torna-se mais macio ao finalmente tocá-lo.

A escrita do ensaio do estágio se experimentou no caminho do desassossego e do questionamento do lugar da neutralidade gerado logo nos primeiros meses de frequência no local. A partir deste caminho, foi possível ter maior clareza a respeito do que parecia não fazer sentido e, com isto, pensar o lugar de quem o escrevia. Pensar as práticas de quem o escrevia, como se fosse possível obter uma visão panorâmica de onde se está. E nesta visão, perceber que quem tece a escrita encontra-se ali, no mesmo cenário em que tudo acontece e, logo, faz parte de todos os processos. A questão passou a ser como fazer parte e, para isto, lança-se mão do que ressalta Larrosa (2002):

Do ponto de vista da experiência, o importante não é nem a posição (nossa maneira de pormos), nem a "oposição" (nossa maneira de opormos), nem a "imposição" (nossa maneira de impormos), nem a "proposição" (nossa maneira de propormos), mas a "exposição",

\footnotetext{
${ }^{3}$ Conceito que busca uma ruptura com as formas prontas e programadas de existência a fim de que constituam-se resistências e singularidades (Deleuze \& Guattari, 2010).
}

nossa maneira de "ex-pormos." (Larrosa, 2002, p. 25).

Levando a problemática do ponto de vista da experiência, no início do ano de 2017 a ideia de realizar um projeto de trabalho de conclusão de curso, pensando todas as experiências vividas no serviço de saúde, foi amadurecendo. $\mathrm{O}$ olhar passou a buscar sinais que auxiliassem na constante elaboração e desmantelamento de sentidos para o que acontecia ali. E então tudo buscava fazer parte de um caminho que não se acabaria, que não buscava uma linha de chegada, mas sim a infinita reformulação de ideias para que não se pensasse em algo como certo e definitivo. Esta busca passava pelos encontros, pelos afetos gerados, pelo deixar-se afetar e, fazer disto, um meio para que o pensamento nunca se conforme com respostas prontas, com ideias já lançadas e sossegadas. Também passava por compreender que para que algo novo aconteça, é necessário que não se tente prever o futuro, mas sim que se busque o que é elaborado nos encontros e momentos. Os encontros passaram a ser outros, deixaram as formas rígidas imaginadas de como seriam antes mesmo de acontecerem, para dar lugar ao inesperado.

A partir disto, novas possibilidades foram sendo produzidas. $\mathrm{O}$ processo de experiência da cartógrafa no dia a dia do estágio passou por mudanças: se inicialmente isolava-se para não ter contato com formas de pensar diferentes da sua, a partir de então, passou a não mais isolar-se em uma das salas do local. E, por conta de tal deslocamento, não mais deixar de expor suas ideias, não mais deixar despercebido o que poderia ser ferramenta de mudança no meio em que estava. Os deslocamentos realizados pela cartógrafa devêm do movimento constante de análise de implicação que coloca em xeque seus próprios saberes e problematiza suas práticas, questionando saberes especializados. Este foi o processo que permitiu a cartógrafa dar-se conta de que o óbvio não existe e, menos ainda, de que ele não pode ser legitimado. O óbvio, tanto para as práticas que questionava quanto para o próprio fazer 
enquanto estagiária, não poderia ser autorizado, pois ele não abre brechas. Ao contrário, fecha todas as portas e nos sentencia para o assujeitamento, para afetos tristes.

Com o desenrolar do ano de 2017, um projeto de pesquisa foi criando corpo. Com este corpo, seria possível então realizar movimentos ainda mais intensos que talvez proporcionassem maior elucidação do que se tentava problematizar e tensionar. Foram inúmeros movimentos, sem saber o que esperar de cada novo passo que se dava. Este corpo não buscava formatar o que já existia e criar novos padrões de funcionamento. $\mathrm{O}$ corpo que este projeto buscava formar, era um corpo sem órgãos ${ }^{4}$. O principal objetivo da cartógrafa era a produção de algo que servisse de subversão, uma abertura ao devir que explorasse as potências que eram capazes de serem emergidas a cada novo andar pelos corredores repletos de cartazes e informativos sobre saúde e doença que formavam o local. Torna-se importante pensar que, conforme Larrosa (2002), “[...] a informação não deixa lugar para a experiência, ela é quase o contrário da experiência, quase uma antiexperiência." (Larrosa, 2002, p. 21). Deste modo, em um local tão tomado de informações, vale a pena considerar como estamos levando nossos encontros, o que eles produzem e a partir do que se sustentam.

$\mathrm{O}$ projeto de pesquisa perambulou pelas entrelinhas do ensaio produzido no primeiro semestre de estágio, passou por incontáveis processos de problematização e, desta forma, foi ferramenta para que fosse possível fornecer novos sentidos para as vivências de quem o escrevera. Neste momento, vale pontuar que o local de estágio possui um corredor imenso, equipado com muitas salas para atendimento. Uma destas salas faz o papel de setor administrativo do

\footnotetext{
${ }^{4}$ Conceito que inicialmente aparece na obra de Antonin Artaud e, posteriormente, é retomado por Deleuze e Guattari como um conjunto de práticas que penetram na profundidade da realidade estabelecida por formatos padronizados e intensamente funcionais (Deleuze \& Guattari, 1996).
}

serviço, onde concentram-se a maioria das pessoas que atuam no local quando não estão realizando atendimento. Ali, na tão pequena e ao mesmo tempo tão povoada sala 5, desdobramentos no modo de pensar foram possíveis, no sentido de que mesmo permeada por discursos rotulantes, abriam-se brechas para que se discutissem práticas outras, que movimentassem outras formas de entender cuidado e saúde. Como no próprio exercício de escrita, a cartógrafa também se pôs, em um primeiro momento, a perambular pelo serviço buscando afastar-se desses discursos rotulantes.

No entanto, a busca pelo controle dos caminhos pelos quais a pesquisa e o estágio percorreriam afastariam a cartógrafa da dimensão da alteridade. Para que a escrita do projeto pudesse seguir, era necessário que não fosse imaginado como sua versão final ficaria. $\mathrm{E}$, para que isto acontecesse, era necessário que quem o redigira estivesse presente, não em sala separada pela indignação causada ao ouvir algo que pudesse soar sem sentido ou desconfortável pelas colegas de equipe, mas que se pudesse lidar com o que discordava a tal ponto de produzir a diferença, de tornar estranho o que parece banal. Além disto, perceber que tudo é construção e que, ausentar-se em face ao que parece absurdo, é alimentar as mesmas ideias que o constituíram, é deixar que tudo fique como está.

A cartógrafa havia inicialmente então, ao isolar-se do que a atingia de maneira desconfortante, deixado que esta condição se mantivesse. Sobre este distanciamento inicial é interessante notar que Lourau (2004) refere que a não-integração a algo pode ser considerada fortemente instituinte, servindo para outro(s) devir(es). Ou seja, o período de distanciamento constituiu-se como fator importante para que houvesse o processamento do que ocorria e para que fossem desencadeados os processos seguintes. Além disto, sobre a experiência, Larrosa (2002) faz um importante apontamento onde diz que 
a possibilidade de que algo nos aconteça ou nos toque, requer um gesto de interrupção, um gesto que é quase impossível nos tempos que correm: requer parar para pensar, parar para olhar, parar para escutar, pensar mais devagar, olhar mais devagar, e escutar mais devagar; parar para sentir, sentir mais devagar, demorar-se nos detalhes, suspender a opinião, suspender o juízo, suspender a vontade, suspender o automatismo da ação, cultivar a atenção e a delicadeza, abrir os olhos e os ouvidos, falar sobre o que nos acontece, aprender a lentidão, escutar aos outros, cultivar a arte do encontro, calar muito, ter paciência e dar-se tempo e espaço. (Larrosa, 2002, p. 24).

A partir do deslocamento entre o exercício do ensaio e a construção do projeto de pesquisa foi possível constituir a tessitura do seguinte objetivo de pesquisa: mapear como se constituem afetos e suas intensidades através da experiência no processo de constituição do cuidado em saúde de crianças e jovens.

\section{Percursos metodológicos}

O processo metodológico escolhido para a escrita deste trabalho consiste na cartografia. Método proposto por Deleuze e Guattari (1995) que se destaca, conforme elucida Passos e Barros (2010), como metodologia que não utiliza prescrições e objetivos rígidos.

Segundo Deleuze (1990):

Desemaranhar as linhas de um dispositivo é, em cada caso, traçar um mapa, cartografar, percorrer terras desconhecidas [...] É preciso instalarmo-nos sobre as próprias linhas, que não se contentam apenas em compor um dispositivo, mas atravessam-no, arrastam-no, de norte a sul, de leste a oeste ou em diagonal. (Deleuze, 1990, §1).
No entanto, ressalta-se que "não se trata de uma ação sem direção, já que a cartografia reverte o sentido tradicional de método sem abrir mão da orientação do percurso da pesquisa." (Passos \& Barros, 2010, p. 17). Por se tratar de um trabalho que busca andar pelos caminhos que quem o escreve percorre, ressalta-se a importância da escolha da cartografia, que exige uma postura mais instigadora de quem está implicado com a escrita. Deste modo, o método cartográfico "não busca estabelecer um caminho linear para atingir um fim." (Kastrup, 2010, p. 32), mas fazer possível que o sujeito que tece a escrita possa navegar por suas ideias embaralhadas nas estruturas dos prédios que habita e nas relações que se estabelecem entre as vozes e corpos que passam por entre e fora de seus corredores.

Para que seja possível a realização da cartografia, são trazidas importantes questões, sendo uma delas a atenção da cartógrafa. Um dos elementos considerados importantes para a pesquisa cartográfica, no que tange a atenção da pesquisadora, é o rastreio. Quanto ao rastreio na cartografia, a pesquisadora entra no campo de observação sem possuir delimitação do que está buscando pesquisar, tornando isto um objetivo a ser alcançado de maneira imprevisível (Kastrup, 2010). Desta maneira, a autora ainda relata que "a atenção do cartógrafo realiza uma exploração assistemática do terreno, com movimentos mais ou menos aleatórios de passe e repasse [...]. Tudo caminha até que a atenção, numa atitude de ativa receptividade, é tocada por algo." (Kastrup, 2010, p. 42). Isto que o rastreio proporciona, é tomado de sentidos no que se refere ao ambiente no qual esta pesquisa ocorre, sendo este um local percorrido diariamente pela pesquisadora, a qual não delimita especificamente um único objeto de estudo dentro do campo, mas sim o que ocorre nos cenários corriqueiros entre cada encontro (e desencontro). A partir disto, pode-se realizar a pesquisa sem o apontamento de nomes, de identidades, mas sim do que chama a atenção nas relações estabelecidas, nos momentos que se constroem a cada passo 
e o que surge a partir deles. Outro elemento importante para a produção da pesquisa, é o reconhecimento atento. Neste quesito atencional, Kastrup (2010) elucida:

O que fazemos quando somos atraídos por algo que obriga o pouso da atenção e exige a reconfiguração do território da observação? Se perguntamos 'o que é isto?' saímos da suspensão e retornamos ao regime da recognição. A atitude investigativa do cartógrafo seria mais adequadamente formulada como um 'vamos ver o que está acontecendo', pois o que está em jogo é acompanhar um processo, e não representar um objeto. (Kastrup, 2010, p. 44).

Neste sentido, não se trata de pesquisar algo que conhecemos enquanto objeto e traçarmos um plano linear de pesquisa, mas sim de construir o que está sendo observado no decorrer do processo de pesquisa. Sendo assim, "o presente vira passado, o conhecimento, reconhecimento." (Kastrup, 2010, p. 46). Deste apontamento surge a importância do deixar-se estranhar e jogar-se na abertura para o inesperado, sem que se busque algo já representado, de transitar por onde ideias estrangeiras transitam, de buscar nas possibilidades de encontro algo novo e assim compor o cenário da pesquisa.

Importante destacar que o método cartográfico, difere-se do método da ciência moderna, conforme Barros e Kastrup (2010) "[...] o caminho da pesquisa cartográfica é constituído de passos que se sucedem sem se separar." (Kastrup, 2010, p. 59). A tomar esta reflexão, esta pesquisa se beneficia de ferramentas que chamam a atenção da autora para os cenários que disparam os pensamentos para a escrita. Ferramentas estas que não buscam enquadrar-se no que pedem documentos como prontuários, fichas de evolução, testes ou qualquer outro instrumento que possa identificar sujeitos. Mas sim utilizar-se de livros, obras ligadas à arte tais como filmes e músicas que podem ser acionados para exercer o pensar no momento em que a pesquisa ocorre. Desta maneira, este trabalho não busca a identificação de práticas isoladas, de estudos de caso, ou o estabelecimento de formas. Mas sim, um novo cenário composto através da própria experiência, a busca do que difere daquilo que já foi encontrado, ou seja, o trabalho fala de um caminho iniciado em julho de 2016 com final previsto para julho de 2018, de suas transformações, de seus desdobres, seus (des)encontros e possibilidades.

Além disto, procura-se estabelecer uma linha que traga elementos das vivências enquanto reflexões, sem atribuir às falas os nomes daquelas e daqueles que as expressam. Assim como se pode acompanhar no trecho abaixo conforme Alvarez e Passos (2010):

Nesse sentido, o conhecimento ou, mais especificamente, o trabalho da pesquisa se faz pelo engajamento daquele que conhece no mundo a ser conhecido. É preciso, então, considerar que o trabalho da cartografia não pode se fazer como sobrevoo conceitual sobre a realidade investigada. Diferentemente, é sempre pelo compartilhamento de um território existencial que sujeito e objeto da pesquisa se relacionam e se codeterminam. (Alvarez \& Passos, 2010, p. 46).

Ao pensar a construção de conhecimento com a reflexão citada, utiliza-se do diário de campo que foi escrito durante o primeiro semestre de estágio no local, atendo-se ao processo de transformação que o mesmo percorre e quais possibilidades são possíveis a partir do pensamento que foi transcrito, acionando novas possibilidades de olhares. Tal ferramenta torna-se interessante para esta pesquisa ao ponto em que faz parte de um caminho já percorrido, que pode (e deve) ser lembrado para novamente ser questionado, embaralhado. 


\section{A (des)construção de certezas}

Escrever (e questionar) a própria prática enquanto estagiária no campo da saúde fazia-se tão necessário quanto qualquer outra tarefa demandada no local de estágio. Era desta forma que cada vez mais se fazia possível construir e, instantaneamente, desconstruir pensamentos. $\mathrm{O}$ exercício era constante e foi mostrando que, para haver mudanças, o que era mais necessário eram presenças. Presenças que estivessem dispostas a abrir uma conversa sobre um comentário, que quebrassem o muro que separa o bom do mau, o preto do branco, a saúde da doença. As reuniões entre estagiários(as) e profissionais da saúde eram capazes de estremecer as barreiras que insistem em fazer-nos pensar de maneira dualista, ao ponto em que faziam a cartógrafa questionar-se em como pode se afirmar que existam tão poucas possibilidades nas vidas de determinadas pessoas. A cada instante foi preciso fazer o exercício de como não fazer uso de documentos, escritas, testes, livros e teorias de maneira não rotuladora, sem que se tentasse enquadrar sujeitos em um ideal desejado ou em um patológico amedrontador.

Cada processo, do início do atendimento até a alta de cada pessoa, parecia ser blindado com um número limitado de possibilidades para dar conta da demanda que era trazida. Nas reuniões de matriciamento ${ }^{5}$, a cada término de fala que relatava um caso trazido para ser atendido no serviço, havia uma discussão sobre os possíveis motivos da criança ou jovem encontrar-se em determinada situação. Na grande maioria dos casos, entendia-se que a parte com maior responsabilidade pela situação atual das pessoas que seriam atendidas era causada por incidentes que ocorreram em/por suas famílias. O que chamava a atenção era que, embora houvesse a possibilidade de relação entre alguns dos ocorridos e o estado atual de determinada criança ou jovem, a primeira

\footnotetext{
${ }^{5}$ Reunião onde "duas ou mais equipes, num processo de construção compartilhada, criam uma proposta de intervenção pedagógico-terapêutica" (Chiaverini, 2011, p. 13).
}

memória adquirida sobre uma pessoa, era o que de ruim havia lhe acontecido para que chegasse naquele serviço. Bernardes (2012) ressalta que, na modernidade,

a população torna-se estatisticamente normatizada pelos processos de categorização individuais: família, criança, mulher, idoso, trabalhador, doente, desempregado. [...] ou seja, a cada uma dessas categorias sociais, se estabelecerá um conjunto particular de estratégias de governo. (Bernardes, 2010, pp. 181, 182).

Tudo então parte da família. Da constituição de uma família. Conforme Bento (2008), "no Brasil colônia, assistíamos ao modelo de família tradicional, extensa e patriarcal. Com o fim do trabalho escravo e a proclamação da República, houve a proliferação do modelo de família nuclear burguesa (pai, mãe e poucos filhos)" (Bento, 2008, p. 203). Isto nos leva a refletir que "atualmente, essa configuração familiar ainda existe, e tem predominância sobre os demais tipos de constituição da família" (Oliveira, 2009, p. 26). O estranhamento e preocupação causada nos(as) profissionais que atendem famílias com outras configurações, acompanha o discurso de que as crianças podem não receber as orientações adequadas para um bom desenvolvimento, já que não possuem uma família dentro dos padrões exigidos, uma família "estruturada". Também neste ponto, esclarece-se que "a noção de desenvolvimento é uma construção, pois não há um conjunto de características a serem obtidas" (Coimbra, Bocco \& Nascimento, 2005, p. 7). Historicamente é possível observarmos que, ainda no século XVIII segundo Foucault (1979):

a família não deve ser mais apenas uma teia de relações que se inscreve em um estatuto social, em um sistema de parentesco, em um mecanismo de transmissão de bens. Deve-se tornar um meio físico denso, saturado, permanente, contínuo que envolva, 
mantenha e favoreça o corpo da criança (Foucault, 1979, p. 199).

Com isto, ficava muito difícil que qualquer discussão que nascesse fora da sala de matriciamento, tomasse outros rumos, outros caminhos que fugissem da doença e da culpabilização da família. Que condições de possibilidades estavam atravessando aquelas vidas para que determinados fatos acontecessem? Não poderia ser tão simples quanto dizer que um(a) filho(a) é agressivo(a) pelo fato de ter uma mãe que lhe "dava umas palmadas" quando pequeno(a). Torna-se importante não deixar que o olhar tome o rumo para um determinismo do ambiente e tampouco do sujeito, ao perceber que "diversas são as tentativas que buscam fixar a força subjetiva produtiva e dar-lhe uma determinada direção." (Mansano, 2009, p. 111). Da mesma forma, compreender que a "produção de subjetividades, da qual o sujeito é um efeito provisório, mantém-se em aberto uma vez que cada um, ao mesmo tempo em que acolhe os componentes de subjetivação em circulação, também os emite, fazendo dessas trocas uma construção coletiva viva." (Mansano, 2009, p. 111).

Quando concebemos a noção de infância como algo que não é natural, mas que começa a ganhar notoriedade no século XIX (Santos, 2004), tornamos possível dirigir nossa atenção aos processos que envolvem seus cuidados e para as gradativas modificações pelas quais passaram no decorrer dos anos. Processos estes que constituíram condições de possibilidade para que ocorresse a participação do Estado na prestação de atendimento à "menores", ainda que em menor escala do que as entidades privadas, buscando fazer com que as ações da classe médica fossem voltadas para a formação de um novo modelo familiar: a família rica e nuclear. (Cruz, Hillesheim \& Guareschi, 2005). Diante isso, concebemos que a infância passa a ser um conceito construído tanto histórica quanto geograficamente, onde perpetuavam-se ideias higienistas no Brasil.
Nota-se também que ao falar sobre a "adolescência" é preciso estar atento para o fato de que, "no século XX, embasado em pressupostos científicos, o adolescente moderno típico estabeleceu-se como um objeto natural com características e atributos psicológicos bem demarcados" (Coimbra et al., 2005, p. 4). $\mathrm{Na}$ contemporaneidade, segundo as mesmas autoras, "a figura do adolescente costuma remeter a uma tendência ditada pelos teens estadunidenses - modelo de todo um estilo de vida a ser consumido pelo restante do mundo [...]" (Coimbra et al., 2005, p. 4). No decorrer das práticas do estágio, foi possível mapear, conforme esclarecido pelas autoras que este modelo "conta com o apoio de algumas práticas da própria psicologia ainda hoje hegemônicas - na propagação e fortalecimento de tal modelo" (Coimbra et al., 2005 , p. 4). É possível verificar isto na equipe ao ouvir discursos da área "psi" que afirmam a "adolescência" como uma fase em que os sujeitos devem ter muito demarcado seu espaço no lugar onde residem, valorizando que se tenha um quarto de uso exclusivo para que possam deixar com "sua cara". Como justificativa aponta-se que neste momento da vida, o(a) "adolescente" passa por muitas descobertas e que ter seu próprio quarto é fundamental. Com a adolescência, carrega-se a noção de um processo linear do desenvolvimento humano, "sendo uma etapa do desenvolvimento pela qual todos passariam obrigatória e similarmente" (Coimbra et al., 2005 , p. 4), ainda que a realidade das pessoas que passam pela Equipe de atendimento seja muito diferente desta que se idealiza.

A partir deste deslocamento com relação à noção de adolescência, também podemos tensionar os tipos de cuidado que propõe o Estatuto da Criança e do Adolescente (ECA), documento considerado fundamental para o estabelecimento de políticas de assistência para crianças e jovens, produzindo um material que exalta os direitos dessas populações, mas não abrange o cotidiano dos diversos tipos de famílias existentes (Cruz et al., 2005). Torna-se importante ressaltar aqui que "o ECA trouxe, à época de sua 
implantação, significativos avanços, sobretudo no que se refere à desconstrução da lógica menorista presente nos códigos anteriores" (Coimbra et al., 2005, p. 5). De tal maneira, com este desassossego, não se busca desqualificar o documento, mas sim tencionálo para que não se torne apenas uma ferramenta de enquadramento de vidas jovens.

Torna-se relevante esclarecer que neste trabalho a cartógrafa não busca desapropriar a importância que as práticas de cuidado em saúde de crianças e jovens na rede pública possuem, porém torna-se importante ficarmos atentos a quais famílias damos maior importância no surgimento de determinadas questões entendidas como problemas, pois podemos refletir que, por exemplo, "embora dirigido a todas as crianças, apenas as pobres chegam ao conselho tutelar vítimas de maustratos e negligência familiar, o que leva a pensar que, na inexistência de carência material, não se dá visibilidade a esta questão" (Cruz et al., 2005, p. 46). Aos poucos foi se antepondo a importância de pensar o porquê se fala tão pouco sobre o que de potente aquelas pessoas que buscavam atendimento produziam; esta inquietação fez emergir na cartógrafa o desassossego ao perceber que todo um funcionamento gira ao redor do que de pior pode ocorrer com determinadas vidas o olhar direcionado ao negativo, sem que se pense em elevar suas potências afirmativas de vida. Ressaltado este ponto, Scheinvar (2006) ainda denota que

perante a falta de condições para se constituir o modelo de família considerado "certo", o sequestro do direito à família vem ocorrendo, historicamente, pela intervenção na relação com os filhos [...]. Isto ocorre seja retirando os filhos fisicamente ou desqualificando seus saberes e suas ações tanto com classificações estreitas como a de "família desestruturada" [...] (Scheinvar, 2006, p. 50).
Chama a atenção da cartógrafa que, embora o local seja um espaço ocupado pela especialidade em saúde de crianças e jovens, é possível perceber que a grande maioria das discussões eram estabelecidas com enfoques na doença. O perigo em ajustar o foco das lentes de profissionais e estagiários(as) da área da saúde apenas para o que pensamos ser o causador de sofrimento em determinado sujeito, é que muito facilmente deixamos de lado as potencialidades que este carrega consigo. Escancara-se aquilo que se acredita ser o mais terrível da pessoa e somente a partir disto são pensadas as estratégias que estão enraizadas em manuais. Com isto, eleva-se a individualização dos problemas de cada um e cada uma, centrando no ser, no sujeito.

Com o pensamento de Nietzsche (2000) sobre a noção de grande saúde, é possível traçar rotas de fuga que fujam de práticas deterministas. Isto passa a ocorrer no momento em que se entende que os movimentos potentes no processo de cuidado em saúde exigem a afirmação da vida, de sua potência. Com isto, o autor explica que "sem dúvida, há muitos meios de encontrar a saúde atualmente; mas é necessário, antes de tudo, reduzir essa tensão do sentir, esse fardo opressor da cultura." (Nietzsche, 2000, p. 169). Nietzsche (2008) nos fala da grande saúde, como algo que não pode ser definido, mas "de uma saúde que não somente se possui, mas que se deve também conquistar sem cessar, porquanto sem cessar é sacrificada e precisa ser sacrificada!" (Nietzsche, 2008, p. 304). O filósofo ainda ressalta o valor da doença, entendendo-a como parte de uma vida que carrega potência, ao exemplificar que "o homem que jaz doente na cama talvez perceba que em geral está doente de seu ofício, de seus negócios ou de sua sociedade, e que por causa dessas coisas perdeu a capacidade de reflexão sobre si mesmo: ele obtém esta sabedoria a partir do ócio a que sua doença o obriga" (Nietzsche, 2000, p. 193, 194). Ao pensar estas questões, que tipos de lentes estaríamos lançando mão para tomar nossos encontros? Como estaríamos entendendo o conceito de saúde? 
Embebida por essas reflexões, a cartógrafa percorre a cena em que uma profissional da área médica do serviço atendia um casal, pais de uma menina de onze anos que estava iniciando atendimento. Ao relatar para as colegas como havia ocorrido o atendimento, estava presente o discurso de que os pais teriam de passar mais tempo de lazer com a menina, pois como trabalhavam muito, chegavam tarde e não tinham condições de estabelecer maiores relações interativas com ela. Os pais justificavam dizendo que já haviam tentado por diversas vezes, mas sempre acabavam brigando (entre eles e com a menina), então achavam melhor a menina já estar dormindo no horário em que chegavam. A médica ainda insistiu, dizendo que era responsabilidade de pai e mãe passar um tempo de qualidade com seus filhos. A fala da mãe, contrapondo a exigência da médica, explicou que nos domingos quase sempre conseguiam passar bons tempos juntos, já que não estavam tão cansados e sentiam-se mais dispostos. Neste momento, a cartógrafa percebe uma grande oportunidade de falar sobre estes momentos, habitados por encontros alegres e cheios de potência. A fala da profissional quanto a isto, foi retomar que pai e mãe não podem ser "só de final de semana". Ao indagar sobre o caso para a profissional que estava atendendo a família, a cartógrafa obtém a informação de que a menina passa muito tempo com sua avó materna, que mora junto com ela e o casal. Questiona-se se a avó se incomoda de ficar com a menina. A resposta nega qualquer problema que esta avó possa ter em ficar com sua neta, mas vem reforçando que a menina "não é filha dela", por isto, não justifica a "ausência" dos pais.

Interessa marcar que a menina havia sido encaminhada por problemas de aprendizagem, mas no matriciamento achou-se importante primeiro passar por uma especialidade médica antes de iniciar atendimento em grupo de aprendizagem que ocorre no serviço. A ideia desta triagem antes do encaminhamento para o grupo, vem acompanhada da interpretação dada pelo serviço de que a incapacidade na escola advém de problemas de rotina em casa, de uma rotina "doente". Nesse encontro, a cartógrafa mapeia outras linhas possíveis ao questionar a rotina "saudável" esperada pela médica e sua ligação linear com o que nos é passado de informações a todo instante. Não apenas nas formações de grande parte dos cursos de saúde, mas também através da grande mídia com suas novelas, jornais, revistas e filmes hollywoodianos. Assim, desde muito cedo, somos tomados pela ideia de que tudo o que é o oposto disto é errado e vai contra a moral estabelecida. Desta forma, o pensamento de Nietzsche (2000) segue nos fazendo tensionar o conceito de saúde (e doença), dizendo que

cada pessoa deve ter uma opinião própria sobre cada coisa a respeito da qual é possível ter opinião, porque ela mesma é uma coisa particular e única, que ocupa em relação a todas as outras coisas uma posição nova, sem precedentes. Mas a indolência que há no fundo da alma do homem ativo impede o ser humano de tirar água de sua própria fonte. - Com a liberdade de opiniões sucede o mesmo que à saúde: ambas são individuais, não se pode criar um conceito de validade geral para nenhuma delas. $\mathrm{O}$ que um indivíduo necessita para a sua saúde é, para um outro, motivo de doença, e vários caminhos e meios para a liberdade do espírito seriam, para naturezas superiormente desenvolvidas, caminhos e meios de servidão (Nietzsche, 2000, pp. 192193).

Se cada realidade perpassa tantas outras, a solução para que se possibilite novas construções de vidas não pode centrar-se de maneira individualizante, culpabilizante e totalizante. Isto levaria a caminhos tomados de impossibilidades, frustrações para aquele(a) que é atendido(a) e para quem atende, tomando os encontros de afetos tristes. Desta forma, os pensamentos que borbulhavam na cabeça da cartógrafa chegavam à escrita deste 
trabalho de conclusão. Embora carregue 'conclusão' em seu nome, a cartógrafa entende que se trata de mais um artefato para que seja possível seguir gerando novos caminhos, ao invés de fechá-los. Abrir caminhos para que se possibilite cada vez mais o diálogo e construção de possibilidades outras.

A partir da perspectiva da construção do modelo de família, é possível estabelecer conversas abertas aos caminhos da diferença com os(as) profissionais que atuam na saúde, evitando produzir discursos culpabilizantes, como se seus modos de pensamento e atitudes fossem oriundos de algo natural. Importante notar que "estamos acostumados a pensar que a configuração do nosso saber sobre a doença é resultado direto da eficácia em combater o sofrimento e em reinstaurar a saúde." (Safatle, 2011 p. 12). Assim, neste modelo naturalizante não se levaria em conta a construção que se produziu sóciohistoricamente.

A cartógrafa passa a perceber que o grande número de faltas e abandonos do serviço, pode ser entendido como sinal de que o entendimento e desenrolar das práticas, talvez não estejam alcançando uma dimensão que estabeleça o diálogo com as experiências destas famílias - de forma a não compor processos de singularização e de autonomia. Tal conjuntura supostamente pode ter como um de seus efeitos que estas pessoas não frequentem mais o local em busca de atendimento. Ao considerar isto, o tensionamento dos espaços de encontro e do que surge a partir deles parece ser um caminho potente para se entenda melhor o que se produz enquanto práticas de cuidado.

\section{A anamnese e a(s) possibilidade(s) de encontro(s) com as pessoas que frequentam o serviço}

Os encontros marcados a partir da anamnese $^{6}$, esta ficha que busca por todos os

\footnotetext{
${ }^{6}$ Formulário utilizado na área da saúde para recolhimento de informações sobre as pessoas que são atendidas.
}

cantos algo que parece ser tão importante com sua minúcia de detalhes explorados, que penetra fundo na vida dos sujeitos que à ela conferem tantas informações, que produz tantos recortes fechados das vidas que por ela passam, passa a chamar a atenção da cartógrafa. Ao iniciar o processo de problematização de tantas anamneses realizadas no decorrer do estágio, o questionamento do saber que a ferramenta se propõe a construir surge como algo potente para as práticas no local. Como poderia ser possível iniciar um encontro que se abra ao sujeito, se utilizamos uma ferramenta que nos cobra informações tão específicas e detalhadas? Que dados são estes recolhidos por este formulário? Para que(m) serve $(\mathrm{m})$ ? Busca por dados que possam auxiliar no processo de atendimento em saúde ou caça padrões? As ferramentas que perpetuam o cotidiano do fazer em saúde não são neutras, elas carregam consigo determinados objetivos. Neste ponto, entende-se a "necessidade de situar a saúde não como um objeto natural da ciência, e sim como um acontecimento que a torna tanto legível quanto real no que tange às práticas de cuidado e às políticas públicas." (Bernardes, 2012, p. 175). Ao compreender isto, há menos chances de que nossas práticas sejam rotulantes, estigmatizantes.

Pensar os movimentos instituintes e instituídos do local torna-se importante ao refletir que as instituições "produzidas pela história [...] acabam por aparecer como fixas e eternas, como algo dado, condição necessária e trans-histórica da vida em sociedades." (Lourau, 2004, p. 73). Neste ponto passa a ficar mais claro para a cartógrafa que provocar deslocamentos e problematizar metas e propostas no campo são atitudes necessárias para manter-se em movimento instituinte.

As cenas em que a cartógrafa se senta em frente às crianças, jovens e suas famílias para realizar entrevistas de anamnese são muitas. Porém, os relatos experienciados carregam consigo alguns trechos em alto relevo. Trechos que fazem parte de um total de três folhas de ofício que pedem nome, 
endereço, cor, idade, onde e com quem determinadas pessoas vivem. Qual o material da casa, quantas peças possuem, se é alugada ou própria. É tinta impressa em papel que percorre cada entranha da vida de pessoas que estamos acabando de conhecer, mas que por termos uma ficha completa, pode nos fazer cair na maldição de acreditar que já sabemos o suficiente para lançar hipóteses a respeito de como vivem e de como seria a melhor maneira para viverem, fazendo com que as práticas sejam pensadas, muitas vezes, na dimensão dos riscos que podem levar à situações mais graves. Sob esta ótica, passa-se a entender que assim como no século XVIII, conforme tensiona Donzelot (1980), as crianças mais bem assistidas, do ponto de vista médico, eram aquelas que dependiam da Assistência Pública, evitando situações perigosas. Também no contemporâneo é possível notar isso pela intensa cobrança de que os(as) responsáveis pela criança ou jovem, ao menor sinal de "desvio" do que é esperado para determinada idade, seja acompanhado mais de perto por um especialista.

Robert Castel (1987) nos conta das ocorrências transformadoras na maneira de manipular a população, onde não mais ocorre o controle sobre patologias ou sintomas, mas sim dos riscos que determinadas populações correm ao se desviarem do que é esperado para um(a) cidadã(o) comum. Além disto, o autor chama a atenção para o fato de que "um risco não resulta da presença de um perigo preciso, mas da colocação em relação de dados gerais impessoais ou fatores (de risco) que tornam mais ou menos provável o aparecimento de comportamentos indesejáveis." (Castel, 1987, p. 125). E assim, a anamnese ainda segue. Ela ainda precisa coletar a informação de como se alimentam, que horário dormem, o que fazem aos finais de semana e com quem. E a solicitação extra: "pode me contar um dia da tua rotina?". A anamnese espera rotina, espera comportamentos bem enquadrados, espera traçar caminhos lineares. Além disso, procura estabelecer nexo causal, ao ponto em que a partir das informações que coleta, passa a investigar quais condutas levam os sujeitos aos efeitos encontrados.

Se o olhar dos(as) profissionais voltase tanto para a doença, a anamnese torna-se peça importante no que reforça este processo, que engendra a noção de um cuidado tão intimamente ligado à doença. Uma ficha que, logo no primeiro encontro, busca tantas respostas para perguntas que nem sabemos o motivo de estarmos perguntando. É preciso então desviar o olhar dessa busca pela essência do sujeito e pelas causas de seus adoecimentos. A cartógrafa busca, ao questionar o funcionamento da anamnese, se desvencilhar do olhar da culpabilização dos sujeitos. Busca também traçar uma rota de fuga capaz de entender que não existe essência ou relações de causa e efeito, mas uma série de concatenações que, como num caleidoscópio, fazem movimentos a todo instante para que tudo se transforme. Ao buscar informações que justifiquem de maneira simplista determinados modos de vida, o instrumento da anamnese faz ser possível tão somente ficar no raso da experiência e perpetuar a homogeneidade, negando as diferenças e prendendo os discursos em uma racionalidade dominante numa suposta imagem rígida. Racionalidade esta que define lugares e maneiras de ser, que marca e define como determinadas vidas devem funcionar sem que seja levada em consideração os processos de singularização da história de cada um(a).

Tal rigidez pode ser acompanhada no seguinte fragmento: na ficha de anamnese utilizada no serviço, há um espaço que pede dados da mãe e do pai de quem será atendido. Em certo dia, a cartógrafa estava acompanhando uma entrevista de anamnese onde estavam presentes um menino de oito anos e sua tia materna, onde foi perguntado à criança: "qual o nome de sua mãe?". A resposta veio sussurrada trazendo o nome da pessoa que estava sentada ao seu lado: era a irmã da pessoa que havia gestado menino que o acompanhava. No mesmo instante, a profissional que estava realizando a anamnese 
rebate que aquela ali é sua tia, não sua mãe, questionando se ele sabia o que havia acontecido para que sua "verdadeira" mãe não estivesse presente naquele momento. À essa pergunta, o menino sabiamente responde: "Eu sei que ela morreu, então ela é minha mãe agora”. Neste momento, a cartógrafa destaca o pensamento de Mansano (2009) referente ao que é imposto aos sujeitos como verdade, onde há o esclarecimento de que

resistir hoje se torna uma ação política quando, por exemplo, recusamos o individualismo já tão naturalizado em nosso processo cotidiano e insistimos nos encontros, fazendo circular as invenções microssociais de novas formas de vida que não se revertem em regras universais obrigatórias. (Mansano, 2009, p. 114).

Na mesma linha, a autora ressalta que "a regra universal, ao pretender englobar a totalidade dos indivíduos, comprometendo-os com a obediência, simplesmente inviabiliza o contato com a diferença e com a criação de novas possibilidades de existir" (Mansano, 2009, p. 114). Como efeito desse processo que nega a diferença, a cartógrafa conseguiu perceber em muitos momentos a frustração das famílias ao sentirem-se incapazes de cuidar das crianças por tomarem como verdade um modelo de cuidado a ser seguido, representado tanto em nossas falas enquanto profissionais, quanto em cartilhas educativas expostas no local de atendimento. Estas, assim como esclarece Donzelot (1980) buscam definir fórmulas certeiras que sirvam de orientação para a criação de crianças saudáveis, assim como os livros criados por médicos para as famílias burguesas entre o século XVIII e XIX, sobre criação, medicação e educação das crianças.

Se fosse possível acolher o que significava para aquela criança ter ou não uma pessoa que pudesse chamar de mãe, sem que se pensasse em estabelecer uma regra para que não fosse criada uma "confusão" na vida do menino, conforme a explicação da profissional por ter agido desta forma, talvez potencializássemos o percurso singular constituído pelo menino. Diante disso, faz-se necessário tensionar como a anamnese leva o(a) profissional a uma linha de perguntas que exclui os processos de singularização, movimentos e experiências dos sujeitos, amarrando-os em armadilhas de nexo causal e, em casos como o apresentado acima, tendem a interpretar a diferença como desvio e desestrutura, impossibilitando a abertura para o devir.

\section{Daquilo que busca a diferença}

Como contraponto desta proposta regida por protocolos, o método intuitivo de que nos fala o filósofo Henri Bergson pode servir para que seja possível enxergar para além de um objeto ou situação a ser analisada. Não com o objetivo de destituir a importância da análise, mas para que seja possível obter um entendimento mais sensível ao que nos é apresentado. Sobre este método, Deleuze (1999) afirma que "a intuição não é um sentimento nem uma inspiração, uma simpatia confusa, mas um método elaborado, e mesmo um dos mais elaborados métodos da filosofia." (Deleuze, 1999, p. 7), tornando-se assim fundamental para a problemática deste trabalho.

Para que se possa compreender melhor a intuição, Bergson (2005) realiza o esclarecimento de um conceito importante: a duração. O filósofo diz que "nossa duração não é um instante que substitui um instante: haveria sempre, então, apenas o presente, nada de prolongamento do passado no atual [...]. A duração é o progresso contínuo do passado que rói o porvir e que incha ao avançar." (Bergson, 2005, p. 5). Neste sentido, ao conduzirmos nossos encontros através de recortes rígidos, tomados por ferramentas que buscam enquadrar situações e ditar maneiras de existir, ficamos incapazes de exercer processos de diferenciação e de subtração para que o novo surja. Com isto, negamos a duração, visto que o foco de nossas práticas leva em conta apenas um pedaço daquele 
momento ligado fortemente à relação espacial de onde ocorre. Deste modo apenas se constataria os procedimentos do que fazer ou não em determinadas situações, sem que seja possível perceber as intensidades $\mathrm{e}$ movimentações constantes que cada encontro gera de maneira única.

Por este motivo, torna-se importante não deixar que representações totalizantes tomem os sentidos que poderiam ser experienciados pelo que é gerado nos encontros. Que se possa fugir da diretriz de procedimentos padronizados, daquilo que é dado. A chegada da família até a equipe especializada passa por inúmeros preenchimentos de linhas em documentos que focam na análise sobre determinada situação, não raramente dando ênfase apenas na doença ou na queixa, em um recorte contaminado. A intuição passa então a ser um achado que possibilita experienciar de outras formas os acontecimentos do local, que faz surgir a variação, a diferença, ao focar não em pedaços isolados da vida dos sujeitos, mas deixando rotas de fugas outras, que sirvam de passagem para o devir, que buscam a profundidade da relação que se estabelece. Deleuze (1999) ainda traz que

Finalidade, causalidade, possibilidade estão sempre em relação com uma coisa uma vez pronta, supõem sempre que "tudo" esteja dado. Quando Bergson critica essas noções, quando nos fala em indeterminação, ele não nos está convidando a abandonar as razões, mas a alcançarmos a verdadeira razão da coisa em vias de se fazer, a razão filosófica que não é determinação, mas diferença (Deleuze, 1999, p. 138).

Com isto, pode-se lançar o olhar para como ocorrem os encaminhamentos desde quando a família decide buscar atendimento para a(s) criança(s) e/ou jovem(ns). Procedimento que inicia na Unidade Básica de Saúde (UBS) de referência, definido pela localidade da residência familiar, onde a família é atendida por um(a) profissional da saúde que preenche uma ficha de referência para que seja encaminhada ao serviço especializado e assim aguardar atendimento. Esta ficha de referência possui espaço para que o(a) profissional possa expor o motivo do encaminhamento. Não raramente, o motivo exposto costuma ser breve. Muito mais breve do que o espaço reservado para escrita. E a brevidade costuma ser definida por sentidos rasos: "agressivo", "perdeu o pai", "mãe em situação de rua", "notas ruins no colégio". A história de vida de uma pessoa passa então a ser definida pelo aglomeramento de três ou quatro palavras, como essas descritas acima. Sendo estas palavras as que fornecem o ponta-pé inicial para um longo caminho dentro do serviço de saúde. E qual o próximo passo desta ficha que carrega tanta responsabilidade em tão pouco espaço? A reunião de matriciamento.

No matriciamento, as UBS trazem consigo os documentos de referência para que sejam entregues às especialistas do serviço. A cartógrafa já teve a oportunidade de participar destas reuniões e questionar se há troca de informações outras entre o(a) profissional que atendeu e transcreveu a demanda (ou somente a queixa) e aquele(a) que fará o papel de levar para a equipe especializada. A resposta, em mais de uma ocasião, foi negativa. Alguns fatores que influenciaram para que isto não acontecesse apareceram na fala $\operatorname{dos}(\mathrm{as})$ profissionais, ao falarem que com um número muito elevado de pessoas para atendimento, não havia tempo hábil para que o(a) médico(a) conversasse referente a cada caso. Outras vezes, a fala justificava que não havia necessidade de uma conversa com maiores detalhes tanto com o(a) pessoa atendida, quanto com o(a) profissional responsável por levar o caso à reunião de matriciamento.

Neste ponto, a cartógrafa questiona como as fases do processo de chegada ao serviço e suas maneiras burocratizadas interferem na maneira como acolhe-se os sujeitos em sua primeira chegada à UBS. Ao ponto em que já se inicia um atendimento sabendo que determinado sujeito será 
encaminhado para outro serviço e, com isto, não haveria problema em não haver uma conversa que demandasse mais tempo de fala e escuta.

No momento em que a equipe especializada recebe $\mathrm{o}$ encaminhamento através do documento de referência, os caminhos tomados na reunião de matriciamento percorrem um histórico de possibilidades para que se tenha chegado em determinada situação. Este caminho percorrido é o primeiro momento dentro do serviço em que se busca fortemente respostas que possam servir de base para que se consiga resolver o mais rápido possível a demanda apresentada, com a justificativa de que a fila de espera para atendimento é grande.

É interessante à atenção da cartógrafa, neste ponto de análise, que muitos dos casos passam por atendimento com profissional pediatra antes de entrarem em contato com outras áreas, ainda que a solicitação não tenha sido por atendimento em pediatria. Isto, conforme justificado pela coordenação do serviço, é eficiente ao ponto em que determinadas questões podem ser "manejadas" com a família, necessitando de psicoeducação e, não necessariamente, de um atendimento mais prolongado. $\mathrm{O}$ que estaria então reforçando este procedimento? Para a cartógrafa, o enrijecimento de práticas que servem para docilizar e normalizar sujeitos. Reforça ainda que procurem uma fórmula apresentada por um(a) profissional da área médica que seja capaz de modular a maneira como determinadas pessoas (con)vivem. Tudo passa então a girar a partir do que foi colocado na ficha de referência, sem que se tivesse chances de conversas mais abertas, sem registros e sem carimbos. E a vida dos sujeitos segue... atropelada por formulários, pelo desespero em encontrar respostas rápidas e universais. Assim, a anamnese chega para que se recolha um número ainda maior de dados. O cuidado considerado importante para a cartógrafa, neste ponto, é que ao dirigirmos nossa atenção para o que estamos "recolhendo" com a anamnese apenas para a queixa escrita no documento de referência, estaríamos fadados a enxergar apenas a doença. Pontos que não serviriam como alertas de cautela, passam a serem vistos como urgências a serem modificados.

Em certa entrevista de anamnese acompanhada pela cartógrafa realizada por profissional do serviço, a mãe de uma criança relatou que dormiam juntos no mesmo quarto. Com espanto, a profissional que conduzia a entrevista questionou o fato, destacando que "nesta idade é importante que ele tenha seu próprio espaço, sua privacidade". Contudo, a resposta que a mãe relata, um tanto quanto envergonhada enquanto mexe nos cabelos é que "a casa tem apenas três peças, não tem como ele ter um quarto só para ele". Chama atenção à cartógrafa que existe uma pergunta na ficha de anamnese que questiona quantas peças possui a casa. E esta pergunta já havia sido respondida, passando despercebida pela profissional que conduzia o encontro, o que leva à reflexão de que as respostas passam a ter efeito extremamente burocrático e pouco reflexivo. Sob este ponto de vista, torna-se importante o apontamento que Ribeiro (2013) faz referente ao método intuitivo, dizendo que

o método intuitivo faz voltar a consciência para a duração existente dentro de cada indivíduo, onde os estados interiores não se justaporiam a outros de maneira sucessiva $\mathrm{e}$ atomizada, mas se interpenetrariam, escapando à lei e à medida." (Ribeiro, 2013, p. 102).

Salienta-se que este movimento de esperar a solução através de coleta quase mecânica de informações e transformação da realidade a partir de conceitos generalizados, não é algo que acomete apenas quem trabalha no serviço, mas algo que emerge das próprias famílias que buscam atendimento e entendem que o saber biomédico está acima de qualquer outro. A fala desesperada que muitas vezes relata angústias busca respostas diretas, sem rodeios. A questão aqui para a cartógrafa é que, ao levar em conta só o que emerge do desespero, 
perde-se todo um lado que poderia ser visto como potência para que a vida desassossegasse na direção de outro devir, que não protagonizasse a doença e deixasse de lado as possibilidades de vida movidas pela alegria.

\section{Das armadilhas que não escapamos, mas questionamos}

A cartógrafa também cai nas armadilhas do que se produz na organização, não está imune ao que gera todo o sistema de relações e práticas das quais relata. Certo dia, no decorrer de suas atividades de estágio, a cartógrafa recebe uma ficha de referência de um menino de nove anos. Como motivo de encaminhamento constava uma situação de abuso sexual, o que fez a cartógrafa direcionar sua atenção somente para o fato descrito com duas palavras no verso da folha que segurava. A partir disto, passou a se relacionar com o menino exaltando o que dizia este pequeno aglomerado de palavras. Haviam passado quase quatro meses desde que o fato ocorreu até o momento em que se recebeu a família para $o$ encontro onde seria realizada a entrevista de anamnese. Ao entrar na sala, a cartógrafa tinha como preocupação encontrar pistas, através do que seria coletado na anamnese, de como poderia estar este menino após passar pelo ato que fez a mãe buscar atendimento especializado. Para a surpresa da cartógrafa, a fala do menino veio acompanhada de encontros alegres, da mudança de escola a qual ainda estava conhecendo pessoas novas, da bola que jogava na frente de casa com os amigos da rua, do lanche que fazia com a mãe na carrocinha de cachorro-quente que ficava em frente à casa do seu melhor amigo. Era possível mapear em seus afetos potências de vida, a todo momento.

Foi difícil para a cartógrafa dar-se conta de que cada vez que tocava no assunto, que já não fazia mais sentido na vida do menino, corria o risco de trazer à tona algo que ele já havia desterritorializado, no momento em que colocou sua potência de vida para agir. No entanto, a mãe trazia em seu relato que se sentia culpada pelo que ocorreu, justificando que o fato se deu por ela não conseguir passar demasiado tempo junto do menino, pois tinha dois empregos. Além disto, também estava sendo cobrada pelo conselho tutelar para que o menino fosse atendido. Dessa forma, além dos atravessamentos da própria instituição em que a cartógrafa se encontrava, ainda ocorriam as demandas que vinham de fora do serviço. Demandas estereotipadas, que não levam em conta os processos de singularização da vida dos sujeitos. Pois ora, se o menino já havia, dentro do período em que aguardava atendimento, passado pelo que era necessário para que saísse da condição de pessoa que necessita de ajuda profissional, por que o conselho tutelar atuava como vigilante desta mãe? E quais mecanismos foram úteis para reforçar a culpabilização que esta mãe sentia pelo que ocorreu com seu filho?

Neste momento, não se busca aqui dizer que o acompanhamento do menino na rede pública não seja interessante. Porém, ressalta-se a importância de abrirem-se brechas para outras possibilidades de contato com esta realidade que escapem a demanda construída de tempos atrás, entendendo que talvez o abuso sofrido já não seja a demanda central, conforme registrado com poucas palavras na ficha de referência encaminhada ao serviço.

Ficava cada vez mais evidente para a cartógrafa que são muitos os perigos de uma única história ${ }^{7}$, contada ainda com tão poucos detalhes, detendo-se apenas ao que de pior ocorre na vida de alguém, quando na verdade, se procura a potência de vida. A subversão vem do que somos capazes de descobrir, não do que vem pronto, concretizado. Conforme Naffah Neto (1991):

\footnotetext{
${ }^{7}$ Sobre os perigos de uma única história, recomenda-se assistir ao vídeo $O$ perigo da história única, onde a Nigeriana Chimamanda Adichie conta sua(s) história(s). Disponível através do endereço https://tinyurl.com/yafy $5 \mathrm{snh}$.
} 
é quando nos dispomos a interrogar o silêncio e a contemplar a escuridão que, pouco a pouco, e como que num passe de mágica, das entranhas do vazio começa a brotar uma nova condição de linguagem e de visibilidade, capazes de subverter a nossa experiência ordinária com o brilho do raro, do sutil, do inusitado (Naffah Neto, 1991, p. 35).

Ao ficarem mais claras estas questões, foi possível para a cartógrafa movimentos que trouxessem a liberação do menino do serviço, ao ponto em que o caso também foi discutido com sua supervisora local de estágio, chegando-se a conclusão de que não era necessário a intervenção de especialista da saúde em um menino que emergia tanta potência de vida. Neste ponto é possível perceber como as relações com colegas de equipe fazem com seja possível abrir movimentos inesperados. A cartógrafa não imaginava que este desfecho fosse possível e, por entregar-se ao encontro, algo inesperado foi capaz de surgir na companhia de sua supervisora local.

\section{Considerações finais}

Ao buscar iniciar o processo de conclusão de escrita deste trabalho, a cartógrafa se depara com a incerteza do que "concluir". A escrita que conduziu este trabalho passou por encontrar brechas que tornassem possíveis movimentos de libertação de ideias, onde a cada passo dado e, a cada palavra escrita, não se buscava produzir uma conclusão, mas novos tensionamentos que apontassem para o devir.

O caminho percorrido ao longo de dois anos no local, que fez disparar a escrita, gerou desacomodações na maneira de perceber como se dão os processos na construção das práticas de cuidado em saúde, bem como estas se atravessam e são atravessadas. A busca por esclarecimentos e pistas que fossem capazes de dar conta do que se questionava ao elaborar o projeto de trabalho de conclusão de curso passou por diversas manobras que permitiram encontrar múltiplos enlaces que permeiam o cotidiano de uma equipe especializada em saúde de crianças e jovens. A cartógrafa percebe, o quão importante torna-se buscar o deslocamento daquilo que entende-se como concreto e imutável no que tange determinados saberes. Neste ponto, é possível perceber a importância de reconhecer que tipos de afetos nos movem na direção do cuidado e guiam nossos olhares para aquilo que consideramos importante a respeito do(s) outro(s).

Passa a ser mais claro que para que se pense em ações na área da saúde, podemos tomar todo processo como movimento instituinte, que siga caminhando no que se desenrola no cotidiano das práticas e das experiências que são possíveis através delas. Não é possível prever o futuro, não é possível prever fórmulas certas de cuidado que sejam capazes de dar conta de questões que julgamos serem as mesmas para todos, pois nunca são. $\mathrm{O}$ processo de construção de autonomia dos sujeitos dá-se ao ponto em que sua autonomia é elevada, onde cada pessoa possa ser protagonista dos cenários que compõem sua vida.

Para que seja possível a caminhada entre aquele(a) que busca atendimento e o(a) profissional que atende, é necessário uma busca incessante pela diferença, pelo devir. Ampliar o olhar e alcançar aquilo que foge de toda normalidade, que busca a (re)produção do que já existe, do que já é conhecido. A cartógrafa toma a intuição como algo capaz de possibilitar outros tipos de relações entre sujeitos, entre profissionais da saúde e pessoas que acessam o serviço. Não se trata de excluir uma determinada linha científica, mas de pensar outras relações que não apliquem àquilo que já existe em todas as pessoas que buscam atendimento de maneira padrão. A partir da intuição e do conceito de duração, abrem-se brechas para o indeterminado, para o inventivo.

Deixar para trás o binômio saúdedoença faz parte de entender que não seremos nunca totalmente saudáveis, muito menos 
totalmente doentes, mas que seguimos percursos que não são lineares, que não são capazes de serem traçados de maneira simplista e generalizante. O filósofo Nietzsche transmite a importância de manter o devir para que o novo possa existir e cada sujeito possa abrir passagem para suas vontades e potências sem que suas vidas e saúde(s) sejam rotuladas. A vida é um processo, que dispara afetos à todo momento. Além disto, a cartógrafa passa a entender que as demandas para atendimento não podem ser definidas de maneira particularizada entre a equipe que atende cada caso, mas sim em conjunto com aquele(s) que $\operatorname{passa}(\mathrm{m})$ a ser(em) atendido(s).
As armadilhas que permeiam o local por onde se transita enquanto acadêmicos(as) e profissionais da área da saúde são muitas e talvez percebê-las seja um exercício instituinte. Perceber que saúde não se trata de ausência de doenças, não se trata de prevenir riscos que são pensados a partir de lógicas totalizantes e higienizantes. Perceber que quanto mais se desassossega com relação ao que é apresentado como demanda e tratamento, além de questionar o que nos é solicitado ao receber alguma pessoa para atendimento, faz parte da busca pelo que não pode ser tirado dos sujeitos: sua autonomia e a busca pelo seu processo de singularização.

\section{Referências}

Adichie, C. N. (2009, Julho). Palestra proferida no TED Talks, Monterey (Califórnia) [Vídeo]. Recuperado de https://www.ted.com/talks/chimamanda_ad ichie the danger_of_a single_story?langu age $=$ pt\&utm_campaign=tedspread\&utm_m edium=referral\&utm_source=tedcomshare

Bento, R. (2009). Família substituta: uma proposta de intervenção clínica na adoção tardia. Revista Psicologia-Teoria e Prática, 10(2), 202-214. Recuperado de http://pepsic.bvsalud.org/scielo.php?script= sci_arttext\&pid=S1516$36872008000200016 \& \operatorname{lng}=\mathrm{pt} \& \mathrm{t} \operatorname{lng}=\mathrm{pt}$.

Bergson, H. (2005). A evolução criadora. São Paulo: Martins Fontes.

Bernardes, A. G. (2012). Potências no campo da saúde: o cuidado como experiência ética, política e estética. Barbarói, (36), 175-190. Recuperado de https://online.unisc.br/seer/index.php/barba roi/article/view/2029/2161

Castel, R. (1987). A gestão dos riscos: da antipsiquiatria à pós-psicanálise. Rio de Janeiro: Francisco Alves.

Chiaverini, H. D. (Org.). (2011). Guia prático de matriciamento em saúde mental. Brasília: Ministério da Saúde: Centro de Estudo e Pesquisa em Saúde Coletiva.

Coimbra, C., Bocco, F., \& Nascimento, M. L. D. (2005). Subvertendo o conceito de adolescência. Arquivos brasileiros de psicologia, 57(1), 2-11. Recuperado de http://pepsic.bvsalud.org/scielo.php?script= sci_arttext\&pid=S180952672005000100002\&lng $=$ pt\&nrm $=$ iso.

Cruz, L., Hillesheim, B., \& Guareschi, N. M.

D. F. (2005). Infância e políticas públicas: um olhar sobre as práticas psi. Psicologia \& Sociedade, 17(3). Recuperado de http://www.scielo.br/scielo.php?script=sci arttext\&pid=S010271822005000300006\&1 ng=en\&nrm=iso

Deleuze, G. (1990). ¿Que és un dispositivo?. In: G. Deleuze (Org.), W. F. do Nascimento (Trad.), Michel Foucault, filósofo (pp. 155161). Barcelona: Gedisa. Recuperado de http://eps.otics.org/material/entrada-outrasofertas/artigos/gilles-deleuze-o-que-e-umdispositivo/view

Deleuze, G. (1999). Bergsonismo. São Paulo: Editora 34.

Deleuze, G., \& Guattari, F. (1995). Mil platôs: capitalismo e esquizofrenia (Vol. 1). São Paulo: Editora 34.

Deleuze, G., \& Guattari, F. (1996). Mil platôs: capitalismo e esquizofrenia (Vol. 3). São Paulo: Editora 34.

Deleuze, G., \& Guattari, F. (2010). O antiédipo. São Paulo: Editora 34.

Foucault, M. (1979). Microfísica do poder. Rio de Janeiro: Edições Graal.

Guareschi, N., Lara, L., Azambuja, M., \& Gonzales, Z. K. (2011). Por uma lógica do 
desassujeitamento: o pensamento de Michel Foucault na pesquisa em ciências humanas. Pesquisas e Práticas Psicossociais, 6(2), 196-202. Recuperado de

http://www.ufsj.edu.br/portal2repositorio/File/revistalapip/volume6_n2/G uareschi_et_al.pdf

Larrosa, J. (2002). Notas sobre a experiência e o saber de experiência. Revista brasileira de educação, s/v(19), 20-28. Recuperado de http://www.scielo.br/scielo.php?script=sci arttext\&pid=S141324782002000100003\&lng=en\&nrm=iso

Lourau, R. (2004). Analista institucional em tempo integral. São Paulo: Hucitec.

Mansano, S. R. V. (2009). Sujeito, subjetividade e modos de subjetivação na contemporaneidade. Revista de Psicologia da UNESP, 8(2), 110-117. Recuperado de http://seer.assis.unesp.br/index.php/psicolo gia/article/view/946.

Naffah Neto, A. (1991). O inconsciente como potência subversiva. São Paulo: Escuta.

Nietzsche, F. (2008). A gaia ciência. São Paulo: Editora Escala.

Nietzsche, F. (1998). Genealogia da moral: uma polêmica. São Paulo: Companhia das Letras.

Nietzsche, F. (2000). Humano, demasiado humano. São Paulo: Companhia das Letras.

Oliveira, N. (2009). Recomeçar: família, filhos e desafios [online]. São Paulo: Editora UNESP; São Paulo: Cultura Acadêmica. Recuperado de http://books.scielo.org/id/965tk/pdf/oliveira -9788579830365-02.pdf.
Passos, E., Kastrup, V., \& Escóssia, L. (Orgs.). (2009). Pistas do método da cartografia. Porto Alegre: Sulina.

Porto Alegre, Prefeitura Municipal. (2015). Equipe Especializada em Saúde da Criança e do Adolescente (EESCA). Documento de Referência.

Ribeiro, E. S. (2013). Bergson e a intuição como método na filosofia. Kínesis-Revista de Estudos dos Pós-Graduandos em Filosofia, 5(09). Recuperado de http://www2.marilia.unesp.br/revistas/inde x.php/kinesis/article/view/4501/3311

Safatle, V. (2011). O que é uma normatividade vital? Saúde e doença a partir de Georges Canguilhem. Scientiae Studia, 9(1), 11-27. Recuperado de http://www.scielo.br/scielo.php?script=sci arttext\&pid=S167831662011000100002\&1 ng=en\&nrm=iso

Santos, E. P. S. (2004). (Des)construindo a 'menoridade': uma análise crítica sobre o papel da psicologia na produção da categoria 'menor'. In H. S. Gonçalves, \& E.P. Brandão (Orgs.), Psicologia Jurídica no Brasil (pp. 205-248). Rio de Janeiro: NAU.

Scheinvar, E. (2006). A família como dispositivo de privatização do social. Arquivos brasileiros de psicologia, 58(1), 48-57. Recuperado de http://pepsic.bvsalud.org/scielo.php?script $=$ $\underline{\text { sci_arttext\&pid=S18095267200600010000 }}$

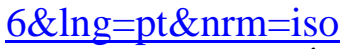

Spinoza, B. (2009). Ética. Belo Horizonte: Autêntica.

\section{Dados sobre os autores:}

- Camila Caroline da Silva Inácio: Psicóloga graduada pelo Centro Universitário Metodista do Sul - IPA, que possui como ênfase do curso de Psicologia as vertentes de Saúde Coletiva e Direitos Humanos. Possui experiência com atendimento psicológico de crianças, jovens e famílias.

- Lutiane De Lara: Graduação em Psicologia pela Universidade de Santa Cruz do Sul (UNISC/2006), Mestrado em Psicologia Social e da Personalidade pela Pontifícia Universidade Católica do Rio Grande do Sul (PUCRS/2009 - Bolsa CNPq) e Doutorado em Psicologia Social e Institucional pela Universidade Federal do Rio Grande do Sul (UFRGS/2015 - Bolsa CAPES). Atualmente, é docente do Curso de Psicologia do Centro Universitário do IPA, coordena o Serviço Escola de Psicologia do IPA e coordena o Observatório de Juventudes na Prisão localizado na Cadeia Pública de Porto Alegre (CPPA). 
